\title{
CONSIDERAÇÕES SOBRE O FUTURO DA HISTÓRIA EM HEGEL
}

Inácio Helfer*

SINTESE - Nos últimos anos de vida do filósofo de Berlim, ele emitiu alguns comentários sobre as dificuldades de o espirito se realizar concretamente na história. A objetivação do espírito estaria enfrentando sérias dificuldades com 0 engendramento geração de uma sociedade livre e autônoma. A determinação concreta da idéia da liberdade, na imediação de um povo, precisa ser projetada para o futuro da história. Estabelecemos, então, considerações sobre o futuro da história em Hegel tentando mostrar como ele não perdeu de vista a correta mediação entre 0 discurso lógico e a explicação objetiva da história, entre a especulação e a objetivação.

PALAVRAS-CHAVE - Hegel, espírito, história, liberdade.
ABSTRACT - In the last years of the philosopher's from Berlin life, he emitted some comments about the difficuities of the spirit to take place concretely in the history. The objective existence of the spinit would be facing serious difficulties with the generation of a free and autonomous society. The concrete determination of the idea of the freedom, in the immediacy of a people, needs to be projected for the future of the history. We established, then, considerations on the future of the history in Hegel, trying to show like him didn't lose of view the correct mediation between the logical speech and the objective explanation of the history, between the speculation and the objective existence (objectiveness).

KEY WORDS - Hegel, spirit, history, freedom.

As últimas reflexões de Hegel nas Vorlesungen über die Philosophie der Weltgeschichte são conhecidas; elas manifestam a inquietude e lamento do pensador face ao espetáculo dos acontecimentos que, de 1785 a 1830, parecem sempre levar para adiante o desenvolvimento da história, deixando subentendido uma hipotética incapacidade do espirito de fixar uma verdade finai:

* Professor de Filosofia nos Departamentos de Ciências Humanas da Universidade de Santa Cruz do Sul - UNISC e Filosofia da Universidade Federal de Santa Maria - UFSM.

1 HEGEL, G. W. F. Vorlesungen über die Philosophie der Weltgeschichte, Band I-IV: Die orientalische Welt, Die griechische und die römische Welt, Die germanische Welt, hrsg. von G. Lasson doravante - citado: WG - Hamburg: Felix Meiner, réed. 1988, p. 932. Numa carta escrita à Christiane Hegel, de 18.01.1831, o filósofo de Berlim escreve: "nosso tempo continua um tempo inquietante, onde aquilo que até nossos dias parecia firme e consagrado parece titubear" (HEGEL, G. W. F. Lettre à Christiane Hegel. Correspondence III, 1823-1831/ HEGEL. Tradução do alemão para o francês de Jean Carrère, texto de Johannes Hoffmeinster. Paris: Gallimard, 1967, p. 283).

\begin{tabular}{|l|l|l|l|l|l|}
\hline VERITAS & Porto Alegre & v. 43 & $n^{0} 4$ & Dezembro 1998 & p. 1009-1019 \\
\hline
\end{tabular}


"após quarenta anos de guerras e de imensa confusão, um velho coração poderia se alegrar de ver aparecer a sua resolução e um apaziguamento; poderia esperar que uma reconciliação durável se instaurasse."1

Já se referindó à história francesa contemporânea, na qual a questão da instauração do Estado verdadeiro não estava ainda efetivamente resolvida, ele se posiciona afirmando que esta "colisão", o "nó", o "problema" "[...] diante do qual a história se encontrava, e que terá que se resolver no futuro", 2 "esta colisão ainda está muito longe de ser resolvida". ${ }^{3}$ Hegel não traduz desse modo uma sorte de dúvida empírica sobre a capacidade do espirito de se afirmar na sua verdade final no Estado Moderno? E, supondo que este seja somente uma exteriorização passageira, evidentemente, a mais alta das determinações desde o começo da evolução histórica do espírito até sua época, não seria necessário afirmar que Hegel projetava para o futuro a realização do fim último da história? Além disso, supondo que tal seja a sua posição, não se deveria afirmar que a descrição histórico-politica do mesmo se apresenta como um discurso que prevê a indeterminação de toda a figuração do espirito? Não seria melhor julgar impossivel toda realização definitiva do fim histórico-político e abrir, desse modo, a história ao progresso infinito?

A tese assim formulada parece não se limitar à constatação da única impossibilidade empírica do espírito de retornar a si. Para um hegeliano, interrogar-se desse modo implica a consideração de um laço essencial subjacente a filosofia, a saber, o laço entre a manifestação mundana do espírito e sua identidade infinita. Em todo o sistema se encontra essa característica. Pensemos, por exemplo, na Filosofia do Direito, cuja leitura mostra claramente que ela opera um desenvolvimento mais completo da Enciclopédia (da filosofia do espirito objetivo da filosofia do espírito) e, ao mesmo tempo, se apresenta como uma exposição mais clara e aprofundada do todo da ciência, e assim, da explicação concreta da Idéia da lógica. Hegel escreve:

"Eu expus de modo detalhado na minha Ciência da Lógica a natureza do saber especulativo; no presente compêndio, em conseqüência, somente agregarei aqui e ali uma elucidação relativa ao processo e ao método. Devido a concreção e o caráter multiforme do ob-jeto, não coloquei em evidência, nem destaquei em cada ocorrência singular a processualidade lógica; de um lado, isto poderia ser considerado supérfluo devido a familiaridade suposta do leitor com o método científico; de outro, nós veremos por si só que o todo, bem como o tratamento de seus membros, repousa sobre o espirito lógico. É desse ponto de vista que eu gostaria que esse tratado fosse compreendido e julgado. Porque o que está em questão nele é a ciência, e na ciência, o conteúdo é por essência ligado à forma."4

A Filosofia da história, com a mesma preocupação, sublinha que

2 Cf. $W G$, p. 933.

3 HEGEL, G. W. F. Vorlesungen über die Philosophie der Religion. Der Begriff der Religion, Teil 1, herausgegeben von Walter Jaeschke, Hamburg: Felix Meiner Verlag. 1993, p. 347.

4 Cf. HEGEL, G. W. F. Grundlinien der Philosophie der Rechts, hrsg. von J. Hoffmeister - citado: $R P h$-, Hamburg: F. Meiner, 1955, Vorrede, p. 4-5. Na "introdução" à Filosofia do Direito Hegel afirma ainda: "A ciência filosófica do díreito tem por ob-jeto a Idéia do direito, o conceito do direito e a realização do conceito," (RPh, § 1, p. 19). "A ciência do direito é uma parte da filosofia. Em conseqüência, ela tem por objetivo desenvolver, a partir do conceito, a Idéia, enquanto esta é a razão de um ob-jeto, em outras palavras, ela almeja apresentar o desenvolvimento imanente da coisa mesma." (RPh \& 2, p. 19). 
"para reconhecer o universal, a racionalidade [na história], devemos levar [subentender] consigo a razão [...] Nosso fim è o de recorihecer esta substancialidade e para a conhecer é necessário tomar consciência da razão; não podemos ver com os olhos naturais, nem pensar com o entendimento finito; é preciso olhar com o olho do conceito, da razão."5

Levando em conta a inseparabilidade sistemática da abordagem históricopolítica e lógica, ou de forma e conteúdo, é necessário se perguntar se a dúvida sobre a realização do fim último da história é compatível com uma consideração sistemática, propriamente filosófica. Sempre preocupado com a coerência, Hegel não cairia na contradição de afirmar o não condicionamento e a não reciprocidade entre esses termos. É necessário então examinar o discurso propriamente filosófico que dá um fundamento e consistência às análises históricas para sondar se há um lugar para uma tal dúvida, para em seguida avaliar as explicações históricas nas quais o "velho coração" hegeliano, as vezes, exprimia sua tristeza face ao curso real da história.

Nesse estudo nossa exposição se limitará ao exame da primeira parte da investigação, ou seja, o problema de fundamentação filosófica da questão.

Com efeito, se admitimos que o espírito absoluto provindo da natureza, do seu ser aí, jamais chega a se pôr como tal de forma absoluta, nos parece que se interpreta assim de modo unilateral o infinito verdadeiro que se situa na posição completamente oposta ao indefinido para Hegel. Supondo que o absoluto a cada vez que se dá à si uma reunificação figurativa de seu movimento de diferenciação, somente chega a uma totalidade provisória de sua auto-superação, este sendo ao mesmo tempo uma determinação que se expõe de novo em sua exterioridade para reconquistar sua unidade mediante a supressão da identidade precedente (que se torna assim abstrata à luz daquela que adveio), este processo de acabamento substancial constituindo o que é próprio do espírito absoluto como tal, nos parece que se afasta da verdadeira concepção hegeliana da evolução histórica do conceito como passagem do abstrato ao concreto se produzindo e se desenvolvendo ele mesmo. Parece claro o seguinte, a determinação absoluta do espírito que se põe como unidade da identidade e da diferença, afirma na sua constituição substancial a omnipresença da antinomia ou da dialética no ser. Contra Kant, Hegel afirma que a

"coisa principal que nós devemos observar, é que não é somente nos quatro ob-jetos par-
ticulares emprestados da cosmologia que se encontram as antinomias, mas antes de tudo
em todos os ob-jetos de todo gênero, em todas as representaçöes, todos os conceitos e to-
das as Idéias. Saber isso e conhecer os ob-jetos segundo essa propriedade, isso faz parte do
que há de essencial na reflexão filosófica."6

Hegel afirma ainda que "essa propriedade constitui o que se determina mais longe como o momento dialético do lógico". "É necessário, portanto, considerar que a constituição do lógico, ou do absoluto, em sua verdade, é concebida na sua

5 HEGEL, G. W. F. Vorlesungen über die Philosophie der Weltgeschichte, Band I: Die Vemunft in der Geschichte, hrsg. von J. Hoffmeinster - citado: VG -, Hambourg: F. Meiner, 1955, p. 32.

6 HEGEL, G.W.F.Enzyklopädie der philosophischen Wissenschaften im Grundrisse (1830), neu hrsg. von Friedhelm Nicolin und Otto Pöggeler - citado Enzy, seguido do volume, parágrafo e página -, Hamburg: Felix Meiner, 1969, v. I, § 48, p. 73.

7

Ibid. 
diferenciação formal por essas três partes: o "aspecto abstrato ou [o que surge] do entendimento", o "aspecto dialético ou negativamente-racional" e o "aspecto especulativo ou positivamente-racional". ${ }^{8}$ Essa concepção privilegia ainda o ponto de vista segundo o qual estes três aspectos "são momentos de tudo o que tem uma realidade lógica, isto é, de todo conceito ou de tudo o que é verdadeiro de um modo em geral"9 e, deste modo, ele é constitutivo da história universal como 0 elemento do qual procede a formação da Idéia efetiva se reconhecendo ela mesma em sua objetividade espiritual.

O primeiro momento do lógico corresponde àquele do pensamento que põe a diferença e sua determinação fixa. $\mathrm{O}$ momento do entendimento é assim 0 ato do eu que nega, na sua imediatidade, o ser dado e o põe como uma coisa que é. $O$ entendimento dá "consistência" às coisas na medida que as explicita, dando às mesmas, é verdade, uma universalidade, mas uma universalidade abstrata. Deste modo, pelo entendimento as determinações se afirmam como fixas, umas em relação às outras, sem levar em conta a instância diferencial que, de fato, põe a presença da "subsistência por si" de cada determinação. O erro do entendimento se encontra pois no modo abstrato de colocar a consistência de alguma coisa face ao particular não reconhecendo que este ato de pôr fixo é (ou existe) somente devido a sua passagem pelo outro.

O segundo momento é aquele da dialética enquanto auto-supressão de tais determinações finitas e sua passagem nos seus opostos pela afirmação que cada uma é somente o que ela é pela sua diferença em relação à outra. Como momento negativamente-racional do Lógico, ou da evolução (histórica) do saber da espiritualização do absoluto que é somente "em si" na natureza, ou que é somente "enquanto sendo por si" e "se tornando em e por si" no mundo (subjetivo e objetivo) do espirito, esse momento já é o "ultrapassar imanente no qual a natureza unilateral e limitada das determinações do entendimento se expõe como ela é, a saber, como sua negação". ${ }^{10} \mathrm{O}$ ser unilateral e limitado das determinaçōes, tudo o que é finito como tal, é somente o ser enquanto se superando a si mesmo. O espírito em sua forma de imediatidade, de indeterminidade que ele tem no seu início, é a realidade que necessariamente progride ou supera sua determinação abstrata, porque essa é uma forma que o contradiz e assim o conduz para frente. A carência em si do ser se torna a força que o leva a se superar dialeticamente. É necessário, portanto, discernir que

\footnotetext{
"o que parece estar presente imediatamente no espirito não é algo verdadeiramente imediato, mas é em si algo posto, mediatizado. Devido a essa contradição, o espírito é levado a suprimir o imediato, o Outro, com o qual ele se pressupõe a si mesmo."11
}

8 Cf. Enzy I, § 79, p. 102.

9 Ibid.

10 Enzy I, § 81, p. 103.

11 HEGEL, G.W.F..Enzyklopädie der philosophischen Wissenschaften im Grundrisse (1830), neu edierte Ausgabe Redaktion Eva Moldenhauer und Karl Markus Michel - citado Enzy, seguido do volume, o termo Zusat2, parágrafo e página -, Frankfurt: Suhrkamp, 1970, v. III, Zusatz. § 385, p. 33. Utilizaremos a edição da Suhrkamp quando precisarmos citar os aditamentos (die Zusätze), uma vez que a edição dos pesquisadores Nicolin e Pöggeler não as apresenta. 
Neste sentido, a dialética é "sobretudo a natureza própria, verdadeira, das determinações do entendimento, das coisas do finito em geral", ${ }^{12}$ porque é por intermédio deste momento que se compreende que o ser subsistindo por si, é somente se pressupondo como provindo de seu Outro, e por esse motivo, da mediação da Idéia se sabendo a si mesma como um sistema científico: "O dialético constitui em conseqüência a alma motora da progressão científica, e ele é o princípio por intermédio do qual somente uma conexão e necessidade imanente se torna presente no conteúdo da ciência". ${ }^{13}$ No plano da histónia universal, a dialética se manifesta como a relação conflitante de diferentes princípios formulados pelo "espírito pensante na vida ética", conflito que produz, de um modo imanente, uma determinidade histórica mais elevada que a precedente na medida que ela nega e conserva em si o movimento do retorno do espírito em sua determinação universal.

No entanto, quando nos limitamos à sua formulação "negativamenteracional", ocorre uma má compreensã́o do "momento dialético do lógico". Como sublinha Hegel, "a filosofia não se limita então ao resultado simplesmente negativo da dialética, como é o caso com o ceticismo. Esse desconhece seu resultado na medida que o sustenta como um simples, como uma abstrata negação". ${ }^{14} \mathrm{O}$ que é necessário levar em conta, portanto - e aqui o hegelianismo se distingue de todo desespero (Werzweifelt) ${ }^{15}$ face à dúvida sobre o progresso propriamente "conceitual" pela dialética (problema do "ceticismo" e da "filosofia crítica"16 ou do "entendimento" em geral até nossos dias) -, é que "enquanto a dialética tem por resultado o negativo, esse é precisamente como resultado, ao mesmo tempo, o positivo, porque contém em si mesmo como suprimido aquilo de que resulta, e não é sem ele." ${ }^{17}$ Se a dialética é antes de mais nada a auto-supressão das determinações do entendimento e sua passagem nos seus opostos, a terceira forma do lógico da Idéia, o momento "especulativo ou positivamente-racional", já é a apreensão da "unidade das determinações na sua oposição", como a compreensão do "resultado positivo" dessas determinações na contradição e passagem em outra coisa. Enquanto "momento especulativo" do lógico, o resultado da contradição, ou do retorno a si do espírito, não cai no "nada vazio, abstrato" do resultado da dialética enquanto uma simples negação abstrata do ultrapassar, como é o caso da compreensão da dialética "tomada à parte por ela mesma pelo entendimento". ${ }^{18}$ Enquanto "momento especulativo", afirma-se que há um fim que consiste no saber do espirito universal compreendido como conceito livre e racional. No plano da história universal, o que o momento especulativo nos ensina, é que a relação conflitante dos diferentes princípios formulados pelos povos históricos não se resume

12 Enzy I, § 81, p. 103.

13 Ibid.

14 Enzy I, Zusatz. § 81, p. 176.

15 Cf. Enzy I, Zusatz. § 81, p. 175.

16 Kant teria desenvolvido com sua filosofia crítica a filosofia cética moderna. Segundo Hegel, porque o ponto de vista da filosofia do mesmo "consiste em simplesmente negar a verdade e a certeza do supra-sensivel, e desse modo designar o sensivel e o que é dado pela impressão imediata como aquilo à que devemos nos restringir" (Cf. Enzy I, Zusatz. § 81, p. 176), sua filosofia desenvolve as determinações que nos fazem permanecer nesse ponto de vista cético. 
no mero retorno a si, teórico e prático, das determinações do espírito compreendidas somente como uma determinação ou uma progressão material e espiritual das civilizações. De fato, a relação conflitante é solucionada pelo retorno propriamente lógico do sistema das Idéias determinadas, como figurações estatais (a história política), que não têm outra finalidade do que a de retornar na Idéia una em sua objetivação, o Estado racional, e, como concepção propriamente filosófica dos sistemas do pensamento (a história da filosofia), que não tem outra finalidade do que a de retornar à Idéia una em sua forma absoluta. Se o momento dialético do lógico afirma a não unilateralidade das determinações do entendimento e sua passagem numa outra coisa, encaminhando assim a realização da contradição da Idéia no tempo, num futuro onde a Idéia teria também o ser na sua plenitude, é necessário ao menos remarcar que, na perspectiva hegeliana, o momento "negativamente-racional" é relativizado pela subordinação concreta ao momento absoluto do absoluto (como Idéia absoluta), momento "positivamente" do retomo da Idéia a si onde todas as determinações do entendimento já retornaram. O que nos ensina a filosofia hegeliana, aquela que se apresenta como a verdade do coroamento de todas as filosofias antecedentes, é que , na Idéia absoluta, o processo de retorno a si da imediatidade já está posto: o que para o entendimento corresponde a um "trabalho difícil", o de "apresentar tudo o que é dito da Idéia [...] como contraditório em si mesmo" - por exemplo, que ainda haja diferenças entre o subjetivo e o objetivo, entre o finito e o infinito, etc. - - de fato, todas as diferenças que o entendimento pretende ainda situar no movimento contraditório temporal do conceito, num movimento infinito, tudo isso "já se operou na Idéia - trabalho que é o trabalho da razão e que, na verdade, também não é fácil como o seu"19 (o do entendimento). Para Hegel se trata de um trabalho muito mais difícil (inclusive impossivel) de provar a omnipresença da dialética no ser (no sentido de um acabamento que se realizaria no futuro), do que provar a relatividade dessa pela subordinação concreta da identidade à si, resultante da contradição completamente desenvolvida da totalidade do ser. O propósito de Hegel é claro:

\footnotetext{
"Até o momento, somos nós que tivemos por ob-jeto a Idéia no desenvolvimento passando por seus diversos degraus; mas de agora em diante [no nivel do momento absoluto do absoluto, o 'momento positivamente-racional'] a Idéia é o ob-jeto para ela mesma."20
}

19 Cf. Enzy I, § 214, p. 183.

20

Enzy I, Zusatz. § 236, p. 388; os termos entre colchetes são de nossa autoria. A Filosofia da história nos informa a mesma coisa: "Digamos que a consciência do povo é a consciência que ele tem de seu ser. O espírito se toma para ele mesmo um ob-jeto; durante o tempo que o mesmo é somente para nós, que ele não se conheceu ainda, ele não é o seu próprio ob-jeto. " (VG, p. 61). Do ponto de vista do espirito absoluto, cujo agir em si - que é sua própria contemplação - se manifesta necessariamente, o espírito é sempre seu ob-jeto. Do ponto de vista do espírito objetivo, daquela consciência que discerne (e penetra) o sentido, o "para nós", o espirito enquanto somente atividade teórica näo se torna por si mesmo um ob-jeto; o espírito se pöe como tal, como teórico e prátj$c o$, enquanto objetividade histórica, uma vez que o mesmo se torna seu próprio objeto: ele é a história conhecida e que conhece, ele é seu próprio processo de diferenciação lógico compreendido como acabado, é a Idéia concebida como sujeito, na forma da liberdade. Se o trabalho de conhecimento da liberdade "para nós" na história da humanidade começou com os filósofos gregos, este conhecimento chegou a seu nivel mais elevado somente com a filosofia especulativa onde o espirito foi reconhecido como sendo em si e para si. 
Até o ponto em que Hegel chegou, a dialética produziu, pelo fato de colocar em relação as determinações subsistentes por si e a supressão das determinações mais abstratas afirmando sempre a superioridade daquela que surgiu, a identidade a si universal do movimento de retorno do espírito absoluto como uma unidade se colocando cada vez mais concreta. Esta verdade é reconhecida pelo filósofo, "nós", e ela é o fruto do esforço de toda a cultura, na qual Hegel mesmo se insere, revelando o sentido dessa interiorização até o ponto onde o conteúdo universal seja apreendido como o idêntico a si no seu movimento de diferenciação. A partir desse momento, o movimento imanente de transfiguração do imediato no mediato foi finalmente compreendido como aquilo que se põe como tal, isto é, se põe não mais como o "nada vazio, abstrato", como um resultado que se torna novamente "um nada imediato" em relação às figurações mais perfeitas que o sucederam este é todo o problema da dialética do entendimento - mas como o concreto enquanto "eternamente razão". ${ }^{21}$

Hegel parece ser suficientemente claro: "a história mundial apresenta uma série de modos de apreender o eterno, no final da qual (an deren Schluß) somente aparece o conceito do espírito absoluto". ${ }^{22}$ Se a história continua, o que segue não é a história universal. Não é o futuro da história lógica que, por intermédio de uma nova cisão de sua determinidade, se colocaria como a reunificação especulativa (mais elevada) da Idéia como tal; se a história continua, se trata da continuação empírica do conceito plenamente revelado a si que, na sua eterna diferenciação, se julga (urteilen) dialeticamente como a afirmação absoluta de seu momento positivo, o que ele já eta em sua positividade desde sempre. Neste sentido, o fim da descoberta desta verdade é somente o começo da dialética enquanto permanente revelação da identidade a si absoluta. Como sugere Hegel, a continuação da atividade do espírito eterno é somente a

\begin{abstract}
"dialética que faz entender, novamente, a esse ser do entendimento, a esse ser diverso, sua natureza finita e a aparência falsa da subsistência por si de suas produções, e que o reconduz à unidade. Enquanto esse duplo movimento não é temporal nem separado e diferenciado, seja de que modo for - de outro modo, ele seria, novamente, somente entendimento abstrato - é a intuiçâo etema dele mesmo no Outro; o conceito que realizou, na sua objetividade, a si mesmo, o objeto que é finalidade intema, subjetividade essencialm23
\end{abstract}

0 "julgamento", a divisão da Idéia absoluta, pressupõe que toda sua determinidade não é outra coisa que ela mesma. ${ }^{24}$ Esta última determinação da autoobjetivação da Idéia, por ser a última, tem as determinações mais abstratas do começo enquanto começo de seu retorno a si até seu conhecimento finalmente acabado, ${ }^{25}$ é o resultado final do desenvolvimento de si mesmo. Nesse nível mais

21 Cf. Enzy I, § 214, p. 184.

22 Enzy III, Zusatz. § 384, p. 31.

23 Enzy i, § 214, p. 184.

24 Cf. Enzy I, § 213, p. 182.

25 O filósofo especulativo é aquele que sabe que o começo não é um imediato vazio: "na progressão da Idéia, o começo se mostra como o que ele é em si, a saber, como o que é posto e mediatizado, e não ccmo o sendo e o imediato. Somente para a consciência em si mesma imediata que a natureza é o que é inicial e imediato, e o espírito o que é mediatizado por ela. Mas, na realidade, a natureza é o que é posto pelo espírito e é o espírito ele mesmo que faz da natureza sua pressuposição.," (Enzy I, Zusatz. § 239, p. 391). 
alto da compreensão do sentido, momento onde termina toda pretensão de ir além - porque não há simplesmente um além: essa compreensão é o "dia da universalidade"26 - o sentido se dá plenamente porque o que ele conhece é a si mesmo, ou, é o saber de seu próprio devenir. Se ainda é o homem que pensa (de fato é Hegel que o escreveu!), ele pensa somente na medida em que é o pensamento, enquanto é o filósofo especulativo, como razão que retorna (história empírica) e já retornou a si (história universal) sem aumentar em nada o saber do que ela sabe, porque é o Si infinito da Idéia. Se até o presente o secretário do absoluto (o filósofo Hegel) revelou o sentido do ser compreendendo a lógica imanente de tudo o que é verdadeiro, de fato ele reconhece que compreendendo o ob-jeto do Si infinito da Idéia, não é propriamente ele que compreende o sentido desse, mas é o próprio espírito absoluto que, por seu intermédio, se faz plenamente manifesto. O saber da Idéia como ob-jeto de si mesmo é um saber adquirido somente pela filosofia moderna, que encontra sua expressão a mais acabada na filosofia hegeliana. Antes dessa, compreensões parciais foram elaboradas por outros sistemas filosóficos, mas estes somente compreenderam figuras sucessivas da única e mesma filosofia, de sorte que cada esforço sintético teve como sentido o processo sempre re-interiorizado do absoluto até sua plena manifestação na filosofia especulativa. A filosofia hegeliana tem a pretensão de ser a última, porque nela o espirito absoluto se compreendeu do modo mais adequado.

Remetendo-se ao retorno a si da história na qual a Idéia absoluta chegou em sua absolutidade na ciência filosófica, Hegel declara nas suas Lições sobre a história da filosofia que

"é este o ponto de vista em que se encontra o tempo presente, e a série de configurações espirituais é, agora, fechada (geschlossen). Desse modo, essa história da filosofia é fechada (Hiermit ist diese Geschichte der Philosophie beschlossen.)."27

O filósofo de Berlim manifesta, assim, sua convicção profunda de que o saber da Idéia do espírito, que a filosofia moderna atinge, termina todo o movimento anterior, concepção que foi antecipada pelas formas ainda não especulativas da arte e da religião, mas que somente foram corretamente expostas pela sucessão dos sistemas filosóficos e a intuição fundamental do pensamento moderno, sob a forma do pensamento especulativo. A progressão da história da filosofia mostra dessa maneira que o conteúdo antecipado nas formas inadequadas da arte e da religião cristã, foi elevado pela filosofia especulativa até a liberação da unilateralidade que ela guardava ainda para ser, finalmente, exposta na "forma absoluta" que, enquanto tal, "se determina ela mesma de modo a ser o conteúdo; e permanece idêntica a si; e nesse sentido, é o conhecimento dessa necessidade que é em e por si." 28 No final da Enciclopédia Hegel diz claramente que "esse movimento, que é a filosofia, já se encontra realizado, enquanto ela compreende, como conclusão, seu próprio conceito, isto é, não faz outra coisa do que reconduzir seu olhar

26 Cf. WG, p. 871.

27 HEGEL, G. W. F. Vorlesungen über die Geschichte der Philosophie. Werke in zwanzig Bänden, Band XX, Teil III, Frankfurt am Main: Suhrkamp Verlag, 1971, p. 461.

28 Enzy III, § 573, p. 451. 
para traz sobre seu saber."29 O saber que a filosofia é somente a reveladora, consiste no reconhecimento que a Idéia absoluta (como filosofia) é "a Idéia que se pensa, a verdade que sabe [...], o lógico com esta significação que ele é a universalidade verificada no conteúdo concreto como na sua efetividade". ${ }^{30} \mathrm{O}$ que a história mundial demonstra em sua objetividade e o que a história da filosofia compreende, de um lado, como sendo o pensamento de seu tempo (da história do mundo) e, de outro, como sendo determinada, a filosofia, ela, pelo próprio movimento do vir a si do desenvolvimento das diferenças lógicas, é o necessário fechamento de seu retorno a si. Enquanto a filosofia no término de seu saber somente lança um olhar para traz sobre o que constitui a obra da Idéia absoluta em seu julgamento, o fim como "término" é necessariamente subentendido. $\mathrm{O}$ discurso hegeliano pressupõe assim que haja um fim da evolução lógica e um fim propriamente histórico, porque uma vez que ela é finita e ao mesmo tempo é condicionada exteriormente pela história sociopolítica, a história mundial também deve ser suposta necessariamente como terminada. Hegel mesmo nos informa que no fim, uma vez que o pensamento chegou a se refletir como sendo ob-jeto de si mesmo, "a ciência" é definitivamente estabelecida. Assim, ela

\footnotetext{
"retornou ao seu começo, e o lógico é de tal sorte seu resultado como o espiritual que, do ato-de-julgar com pressuposições, no qual o conceito estava somente em si e o começo um imediato, para além da apariçäo que ele tinha de si mesmo nesse ato, ele se elevou no seu principio puro ao mesmo tempo como no seu elemento." ${ }^{31}$.
}

Se a ciência no seu início era imediata - pensemos um pouco no longo período "do acordar natural" da consciência em direção a uma concepção mediatizada de si mesma, ou de uma determinação superior do espirito, situação na qual o saber "para nós" não se encontrava no seu "princípio puro", nem no "seu elemento", no nível do saber que se sabe enquanto tal -, é somente a partir desse momento onde tudo o que se verifica na história mundana ou na ciência do entendimento, na renovação do seu começo e seu retorno à Idéia ela mesma, que a ciência é como tal terminada: ela é somente o lógico enquanto resultado espiritual. Com relação à questão inicial: poderia haver um progresso infinito da dialética além dessa verdade? Hegel responde pela negativa. Querer ir mais longe significa retornar - e de fato o espírito absoluto já "retornou", porque ele retorna sempre à sua imediatidade - a seu começo que agora não é somente conhecido "em si", mas também "para nós" como Idéia que "essencialmente" é esse processo segundo o qual "sua identidade é somente a identidade absoluta e livre do conceito na medida em que ela é a negatividade absoluta."32

Quando o entendimento pretende ainda provar (por intermédio de "um trabalho fácil") que o momento absoluto do absoluto não é o que ele é, que o mesmo é exclusivamente o "momento negativamente-racional", Hegel afirma que

29 Ibid.

30 Enzy III, § 574, p. 462.

31 Ibid.

32 Enzy I, § 215, p. 184. 
"a Lógica mostra sobretudo o oposto, a saber, que o subjetivo que seria somente subjetivo, o finito que seria somente finito, o infinito que seria somente infinito, e assim por diante, não têm nenhuma verdade, se contradizem e passam no seu contrário; com isso, esse passar e a unidade em que os extremos estão enquanto superados - como um aparecer ou momentos - revelam-se como sua verdade."33

É no saber do Si infinito da Idéia que, efetivamente, "a passagem" e "a unidade" dos extremos se reencontram em sua verdade como a identidade a si da diferença completamente desenvolvida. A identidade abstrata do infinito não é a unidade unilateral de sua posição de si, mas "a unidade negativa" de sua própria autodeterminação concreta. O infinito é somente absoluto enquanto resulta da superação de sua finitude:

"a Idéia absoluta é o universal, no entanto o universal não simplesmente como forma abstrata à qual o conteúdo particular se põe como um Outro, mas como a forma absoluta na qual estão retornadas todas as determinaçōes, a pleritude total do conteúdo posto graças a ele."34

Se Hegel pressupõe a omnipresença da dialética no ser, é porque o Bem se produz na medida que o pensa no mundo pela negatividade; é por isso que este Bem é sempre subordinado ao terceiro momento, ao positivamente-racional; uma vez que o progresso dialético não cessa, o Bem se realiza completamente no conteúdo universal, racional, do seu movimento de dissolução e de produção de si como uma unidade negativa da Idéia no qual "o infinito se sobrepôs ao finito, o pensamento sobre o ser, a subjetividade sobre a objetividade." 350 movimento no espirito não se dá como o que poderia ir além do "desenvolvimento total" do conteúdo da Idéia absoluta, mas como aquilo que torna vivo a presença desse na imediatidade que retorna sempre na interioridade infinita. Considerando essa realidade segundo o enfoque da estrutura da Lógica, é necessário afirmar que, se o processo dialético é o fato da passagem no outro na esfera do ser, e o aparecer em outra coisa na esfera da essência, na esfera do conceito ele é, por conseguinte, um desenvolvimento pelo qual "é somente posto o que é em si já presente." ${ }^{36} \mathrm{~A}$ dialética no conceito é assim um movimento imanente que desenvolve a totalidade do sentido porque ela contém em si, como suprimido, todas as determinações opostas anteriores do pensamento. No conceito, as oposições abstratas do ser e da essência já estão ultrapassadas porque somente o conceito é "o absolutamente concreto" ${ }^{37}$ A filosofia que se:apresenta como a reflexão desenvolvida do conceito, e que fecha assim todo esforço precedente do pensamento para falar da verdade do sentido, não é um discurso unicamente formal da verdade, ou ainda uma abstração posta a ser ultrapassada no futuro, mas é o pensamento no qual "o conceito é seguramente tomado como forma, mas como forma infinita, criadora, que reúne nela mesma e, ao mesmo tempo, deixa ir para fora dela mesma a plenitude de

33

34

35 Enzy I, Zusatz. \$ 237, p. 389.

Enzy I, § 215, p. 185. "[...] das Unendliche über das Endliche hinüber, das Denken über das Sein, die Subjektivität über das Sein, die Objektivität."

36

37 
todo conteúdo"38 Não é possível então elaborar um pensamento mais contemporâneo do movimento do ser que a compreensão do lógico em sua determinação absoluta. O futuro da filosofia é para Hegel, e para todo hegeliano, a atualidade da especulação filosófica da Idéia absoluta.

Concluímos assim que, se o "velho coração" do homem Hegel manifesta a impaciência face a realização do espírito, não se trata certamente de uma dúvida especulativa sobre a realização efetiva da determinação universal do espírito, enquanto estrutura verdadeira ou definitiva em seu sentido, ou, de um modo mais aprofundado, de seu acabamento propriamente filosófico, mas de uma hesitação face à dificil instauração dele mesmo, como determinação forte e constante, nas dimensões empíricas da vida ética de sua época. Para Hegel, a história da tradução conceitual da identidade a si do espírito termina com o espírito do mundo enquanto Estado racional, no qual se dá o conceito verdadeiro, total de si mesmo. A instauração propriamente empirica é ainda fraca porque a objetivação efetiva do espírito se desenvolve necessariamente no elemento da natureza como um processo de idealização dela, construindo um mundo posto por ela mesma, mas não como a integração completa da particularidade na idealidade da razão: o mundo finito do espírito, assim como a natureza em geral, são o campo onde o acaso e a contingência têm seu livre jogo. No entanto, essa diferença que permanece não tem o poder de comprometer a realização essencial da razão histórica que, em definitivo, se desenvolveu na estrutura do Estado protestante germânico de sua época. De um lado, é uma conviç̧ão para Hegel que o pensamento acaba verdadeiramente seu processo de conhecimento de si com o saber da Idéia absoluta, se bem que, de outro, o saber dessa verdade nos chega necessariamente num primeiro lugar de maneira exterior, isto é, por intermẹdio da prova empírica, o que faz com que o fim da história se imponha como uma suposição obrigatória

\section{Referências bibliográficas}

HEGEL, G. W. F. Enzyklopädie der philosophischen Wissenschaften im Grundrisse (1830), neu hrsg. von Friedhelm Nicolin und Otto Pöggeler, Hamburg: Felix Meiner, 1969.

- Enzyklopädie der philosophischen Wissenschaften im Grundrisse (1830), neu edierte Ausgabe Redaktion Eva Moldenhauer und Karl Markus Michel, Frankfurt: Suhrkamp, 1970.

Lettre à Christiane Hegel. Correspondence III, 1823-1831/ HEGEL. Tradução do alemão de Jean Carrère, texto de Johannes Hoffmeinster. Paris: Gallimard, 1967.

- Grundlinien der Philosophie der Rechts, hrsg. von J. Hoffmeister. Hamburg: Felix Meiner, 1955.

- Vorlesungen über die Philosophie der Religion. Der Begriff der Religion, Teil 1, herausgegeben von Walter Jaeschke, Hamburg: Felix Meiner Verlag. 1993.

- Vorlesungen über die Philosophie der Weltgeschichte, Band I: Die Vernunft in der Geschichte, hrsg. von J. Hoffmeinster, Hambourg : Felix Meiner, 1955.

. Vorlesungen über die Philosophie der Weitgeschichte, Band II-IV: Die orientalische Welt, Die griechische und die römische Welt, Die germanische Welt, hrsg. von G. Lasson, Hamburg : Felix Meiner, réed. 1988.

38 Ibid. 